\title{
On Using Relative Prices to Measure Capital-Specific Technological Progress
}

\author{
Milton Marquis \\ Federal Reserve Bank of San Francisco and Florida State University \\ and \\ Bharat Trehan \\ Federal Reserve Bank of San Francisco
}

March 2005

Working Paper 2005-02

http://www.frbsf.org/publications/economics/papers/2005/wp05-02bk.pdf

The views in this paper are solely the responsibility of the authors and should not be interpreted as reflecting the views of the Federal Reserve Bank of San Francisco or the Board of Governors of the Federal Reserve System. 


\title{
On Using Relative Prices to Measure Capital-Specific Technological Progress
}

\author{
Milton Marquis* \\ Federal Reserve Bank of San Francisco and Florida State University \\ and \\ Bharat Trehan** \\ Federal Reserve Bank of San Francisco
}

March 2005

\begin{abstract}
Recently, Greenwood, Hercowitz and Krusell (GHK) have identified the relative price of (new) capital with capital-specific technological progress. In a twosector growth model, however, the relative price of capital equals the ratio of the productivity processes in the two sectors. Restrictions from this model are used with data on wages and prices to construct measures of productivity growth and test the GHK identification, which is easily rejected by the data. This raises questions about various measures of the contribution that capital-specific technological progress might make to the economy. This identification also induces a negative correlation between the resulting measures of capital-specific and economy-wide technological change, which potentially explains why papers employing this identification find that capital-specific technological change accelerated in the mid1970s. We impose structure on the productivity measures based on their long run behavior and find evidence of a slowdown in productivity in the 1970s that is common to both sectors and an acceleration in the mid-1990s that is exclusive to the capital sector.
\end{abstract}

JEL Classification: O40

Keywords: Productivity, technological change

\footnotetext{
* We thank John Fernald and participants at a Florida State University seminar for helpful comments and discussions and Jeremy Greenwood for his data on relative prices. We also thank Mike Atkinson and Tatiana Balekha for valuable research assistance. Any opinions expressed in this paper are those of the authors and not those of the Federal Reserve System. ${ }^{* *}$ Corresponding author. Phone:(415)974 3207; fax:(415)974 2168; email:bharat.trehan@sf.frb.org
} 


\section{Introduction}

In a recent, influential paper, Greenwood, Hercowitz and Krusell (GHK, 1997) explicitly identify the decline in the relative price of capital with capital-specific productivity growth in a one-sector neoclassical model and conclude that about 60 percent of the growth in U.S. productivity over the 1950 to 1990 period can be attributed to capital-specific technological change. Subsequent papers have used this identification to study a variety of different issues. GHK (2000), using the same identification, find that technological change specific to new investment goods “..is the source of about 30 percent of output fluctuations." Greenwood and Yorukoglu (1997) show that the rate of decline of the relative price of capital accelerated after 1974 and argue that this represents an acceleration in the pace of technical change in the capital goods sector that began in 1974. Other papers that have used the relative price variable to measure capital-specific technical change include Cummins and Violante (2002) and Fisher(2002).

In this paper we take a closer look at the conditions under which the relative

price of capital can be identified with capital-specific technological progress and also discuss some implications of this identification. We begin by constructing a theoretical model that is similar to Whelan(2001) and that contains two sectors: a consumption goods sector and a capital goods sector. In this model, the relative price of capital depends upon the ratio of the productivity processes in the two sectors. Thus, the relative price of capital can fall due either to an increase in the rate of technological progress in the capital goods sector or to a decline in the rate of technological progress in the consumption goods sector. That is, the relative price of capital can be informative on the relative change in productivity between the two sectors, but is not a direct measure of capital-specific technological progress. While the results of some of the papers cited above do not rely on this distinction, many do. Therefore, one purpose of this paper is to add some clarity to this issue.

By imposing the model's theoretical restrictions on aggregate price data, we construct the dual measures of productivity in the consumption and capital goods sectors. These measures are similar to the those developed by Jorgenson and 
Griliches (1967) for a one-sector model and employed, among others, by Oliner and Sichel (2000) and Hsieh (2002). These series enable a test of the restriction on the data that is necessary for the GHK conjecture that the relative price of capital measures capital-specific technological progress to be valid. The conjecture is strongly rejected by the data. The implication is that the relative price of capital cannot be used in isolation to draw inferences about the contribution of capital-specific technological progress to either economic growth or to output fluctuations.

We also take up another key issue in the productivity literature: the long-run structural changes that have taken place in aggregate productivity. As mentioned above, GHK (1997) and Greenwood and Yorukoglu (1997) conclude that capitalspecific productivity accelerated in the early 1970s at about the same time that aggregate productivity slowed down. In contrast, our evidence (using tests due to Bai and Perron (1998)) suggests that TFP growth slowed down in both sectors at that time, which we attribute to an economy-wide slowdown in productivity growth that was more pronounced in the consumption goods sector. This conclusion is consistent with: (i) the full sample estimate of the relationship between the two productivity series, and (ii) evidence that this relationship between the two series is robust across the break. Therefore, a long-run, economy-wide productivity slowdown accentuates the relative price decline in capital goods that GHK and others incorrectly attribute to an acceleration in capital-specific technological progress.

A second major break in aggregate productivity occurred around 1995, when productivity growth accelerated. However, this episode does not appear to have been a reversal of the economy-wide productivity slowdown that occurred in the 1970s. Rather, our evidence suggests that this break is indeed concentrated entirely in capital-sector TFP. As we discuss below, this pattern of breaks in the two series is consistent with a two shock representation of the aggregate productivity process where one shock affects both sectors while the other affects the capital goods sector alone. 


\section{A Two-sector Model}

A two-sector theoretical model is developed in this section with sector-specific technological progress. One sector produces consumption goods, from which households derive utility. The other sector produces capital goods that are used by both sectors as factor inputs in production and as consumer durables that provide utility to households through a stream of consumption service flows.

\subsection{Households}

The economy is populated by a large number of identical households that maximize lifetime utility by choosing optimal paths for consumption bundles, investment portfolios, and time allocations, or:

$\max _{\left\{c^{n}(t), c^{d}(t), x^{d}(t), x^{f}(t), x^{c}(t), n^{f}(t), n^{c}(t), l(t)\right\}} \int_{t=0}^{\infty} e^{-\rho t}\left[c^{n}(t)+\eta_{1} c^{d}(t)+\eta_{2} l(t)\right] d t, \eta_{1}, \eta_{2}>0$

where the instantaneous utility function is log-linear in the consumption of nondurables and services, $c^{n}(t)$, consumption service flows from the stock of consumer durables, $c^{d}(t)$, and leisure, $l(t)$. The household's subjective discount rate is denoted by $\rho \in(0,1)$. The household provides labor to both the capital goods firms in the amount $n^{c}(t)$, and to the consumption goods firms in the amount $n^{f}(t)$, and owns the economy's capital stock comprised of consumer durables, $k^{d}(t)$, as well as productive capital in the capital goods sector, $k^{c}(t)$, and in the consumption goods sector, $k^{f}(t)$. The corresponding gross investments in the capital stocks are denoted by $x^{d}(t), x^{c}(t)$, and $x^{f}(t)$, respectively.

The household faces a budget constraint:

$c^{n}(t)+q(t)\left[x^{d}(t)+x^{f}(t)+x^{c}(t)\right] \leq w(t)\left[n^{f}(t)+n^{c}(t)\right]+q(t) r(t)\left[k^{f}(t)+k^{c}(t)\right]$

where the wage rate, $w(t)$, and the unit price of capital goods, $q(t)$, are both expressed in units of consumption goods, and where $r(t)$ is the real rental rate on 
capital. The household therefore receives labor income, the first term on the righthand side of equation (2), and rental income, the second term. Expenditures are for the purchase of consumption goods, the first term on the left-hand side, and for capital goods, the second term, where gross investments determine the rates of capital accumulation:

$$
\frac{d k^{i}(t)}{d t}=x^{i}(t)-\delta k^{i}(t)
$$

where $i=f, c, d$ assuming that all capital stocks depreciate at the same rate $\delta \in$ $(0,1)$.

Consumption service flows from the stock of consumer durables are assumed to be linear:

$$
c^{d}=\phi k^{d}, \phi>0
$$

The household also faces the usual nonnegativity and time resource constraints.

\subsection{Production Sectors}

The capital goods sector is assumed to be competitive and can be modeled as a single aggregate firm that maximizes profits by choosing its output, $x(t)$, and its factor inputs of capital, $k^{c}(t)$, and labor, $n^{c}(t)$, or:

$$
\max _{\left\{x(t), n^{c}(t), k^{c}(t)\right\}} q(t) x(t)-w(t) n^{c}(t)-q(t) r(t) k^{c}(t)
$$

subject to its Cobb-Douglas production technology:

$$
x(t) \leq \mu(t) k^{c}(t)^{\alpha} n^{c}(t)^{1-\alpha}, \alpha \in(0,1)
$$

Total factor productivity (TFP)in this sector grows exogenously as determined by the evolution of $\mu(t)$, whose growth rate we denote by $g_{\mu}$. 
First-order conditions determine factor prices as functions of the relative price of capital to consumption goods, the firm's TFP, and the marginal products of capital and labor.

$$
\begin{gathered}
w(t)=q(t) \mu(t)(1-\alpha)\left(k^{c} / n^{c}\right)^{\alpha} \\
r(t)=\mu(t) \alpha\left(k^{c} / n^{c}\right)^{\alpha-1}
\end{gathered}
$$

In a similar fashion, the consumption goods sector is also assumed to be competitive and chooses its output, $c^{n}(t)$, and factor employment decisions for capital and labor, $k^{f}(t)$ and $n^{f}(t)$, to maximize profits, or

$$
\max _{\left\{c^{n}(t), n^{f}(t), k^{f}(t)\right\}} c^{n}(t)-w(t) n^{f}(t)-q(t) r(t) k^{f}(t)
$$

subject to:

$$
c^{n}(t) \leq \theta(t) k^{f}(t)^{\alpha} n^{f}(t)^{1-\alpha}, \alpha \in(0,1)
$$

where $\theta(t)$ denotes exogenous technological progress and its growth rate is given by $g_{\theta}$.

As in the case of the capital goods sector, we obtain the following expressions for factor prices:

$$
\begin{aligned}
& w(t)=\theta(t)(1-\alpha)\left(k^{f} / n^{f}\right)^{\alpha} \\
& q(t) r(t)=\theta(t) \alpha\left(k^{f} / n^{f}\right)^{\alpha-1}
\end{aligned}
$$

\subsection{Equilibrium}

The equilibrium that we examine is for stationary time allocations where $x(t)=$ $x^{f}(t)+x^{c}(t)+x^{d}(t)$ for which:

$$
r=\rho+\delta+\frac{g_{\mu}}{1-\alpha}
$$




$$
\begin{gathered}
\widehat{x}=\widehat{x^{f}}=\widehat{x^{c}}=\widehat{x^{d}}=\widehat{k^{f}}=\widehat{k^{c}}=\widehat{k^{d}}=\widehat{c^{d}}=\frac{g_{\mu}}{1-\alpha} \\
\widehat{c^{n}}=\widehat{w}=g_{\theta}+\frac{\alpha}{1-\alpha} g_{\mu} \\
\widehat{q}=g_{\theta}-g_{\mu}
\end{gathered}
$$

Equation (13) expresses the steady-state real rental rate, $r$, in terms of the household's discount rate, $\rho$, the depreciation rate on capital, $\delta$, and the rate of technological progress in the capital goods sector, $g_{\mu}$, adjusted for the factor share on labor, $1-\alpha$. Along the balanced growth path, equation (14) indicates that the last term in the determination of the real rental rate from equation (13), $\frac{g_{\mu}}{1-\alpha}$, is simply the rate of growth of output from the capital goods sector, $\widehat{x}$. Equation (15) indicates that output growth in the consumption goods sector is determined by factor shares in production $(\alpha)$ and the growth in TFP in both sectors, i.e., $g_{\theta}$ and $g_{\mu}$. Equation (16) indicates that the percentage change in the relative price of capital goods to consumption goods is fully determined by the difference between the growth rates of TFP in the consumption goods sector, $g_{\theta}$, and the capital goods sector, $g_{\mu}$.

Note that if you were to follow GHK and add output from the two sectors using the production functions in equations (6) and (10), you obtain the GHK single-sector version of the model, where:

$$
c+q x=\theta k^{\alpha} n^{1-\alpha}
$$

with $q=\theta / \mu$. GHK go on to attribute secular movements in $q$ to capital- or investment-specific technological progress. However, as is obvious from (16) above, the relative price of capital will be affected by changes in productivity growth that affect either sector or even both sectors simultaneously as long as the effect on the two sectors is not exactly the same. In what follows, we construct empirical measures of productivity in the two sectors and study their behavior to 
try and develop suitable representations of these processes and of the relationship between them. We are particularly interested in the conditions under which the relative price of capital can be identified with productivity growth that is specific to the capital sector alone.

\section{Measures of Productivity}

We use the first-order conditions from the production side of our model to derive theoretical expressions for the technology shocks in the two sectors in terms of factor prices and the relative price of the capital goods vis-a-vis consumption goods.

From the equations for wages and rental rates [that is, (7), (8), (11) and (12)] as well as the production technology specified in (6) and (10), the following expressions can be derived for the TFP (technology shocks) series, $\mu(t)$ and $\theta(t)$.

$$
\begin{aligned}
& \mu(t)=\left[\frac{w(t)}{q(t)(1-\alpha)}\right]^{1-\alpha}\left[\frac{r(t)}{\alpha}\right]^{\alpha} \\
& \theta(t)=\left[\frac{w(t)}{1-\alpha}\right]^{1-\alpha}\left[\frac{q(t) r(t)}{\alpha}\right]^{\alpha}
\end{aligned}
$$

These measures are reminiscent of the price-based measure developed by Jorgenson and Griliches (1967) —in the context of a one-sector model — who also pointed out that the quantity- and price-based measures of productivity are dual to each other. For future reference, also note that the relative price, $q(t)$, is given by the ratio of the technology shocks, $\theta(t) / \mu(t)$, or

$$
\widetilde{q}(t)=\widetilde{\theta}(t)-\widetilde{\mu}(t)
$$

where the tilde " " " represents natural logs, e.g., $\widetilde{q}(t)=\ln q(t)$. 


\subsection{The Data}

We now describe how the empirical measures of output, wages, prices and real rates of return are constructed to match the theoretical concepts in the previous section. For the empirical counterpart of the output of consumption goods in the model, we use the output of consumer nondurables and services from the NIPA accounts. The output of capital goods in the model is matched with the output of consumer durables plus producer durable equipment in the NIPA accounts. The aggregation of consumer durables with producer durables follows Whelan (2001), who shows that over the postwar period the behavior of consumer durables (especially relative prices) looks much more like producer durables than consumer nondurables and services. ${ }^{1}$

The relative price of capital is then defined as the price of consumer plus producer durables relative to the price of consumer nondurables plus services. Figure 1 plots this relative price over the 1959-2003 period. To get a measure of the real wage, the series on total compensation per hour in the business sector is deflated by the price index for consumer nondurables and services. The real rate of return on capital is proxied by a constructed measure of the real rate of interest. The results below are based on a measure which subtracts expected inflation from the interest rate on triple-A rated corporate bonds, where expected inflation is defined as a centered five-quarter moving average. To test the sensitivity of our results, we repeated much of the analysis with the 6-month commercial paper rate (instead of the triple-A corporate bond rate) as well as purely backward and forward looking measures of inflation. These changes made no material difference. An alternative would be to use a measure based on after-tax returns on capital, such as the one constructed by Poterba (1997); Cooley and Prescott (1995) suggest a similar measure. We decided against such a measure because it requires a capital stock series, which is only available at an annual frequency. However, as a robustness check on our results, we constructed annual $\theta_{t}$ and $\mu_{t}$ series for

\footnotetext{
${ }^{1}$ Investment in structures is omitted from the analysis, since data reveal little evidence of capital-specific technological progress in that sector. The government sector is also omitted.
} 
the 1959-1995 period using both Poterba's time series and the AAA bond rate used above (since Poterba's series end in 1995). The correlation coefficients for the growth rates of the two sectoral TFP measures are 0.953 and 0.932 respectively while the correlation coefficient for the growth rate of the corresponding economy-wide productivity measure (described below) was $0.956 .{ }^{2}$

Finally, we also need a value for the one parameter that shows up in the equations for $\mu(t)$ and $\theta(t)$ above, which is capital's share of income, or $\alpha$. There is some debate about the exact value of this parameter. Here, we rely on recent work by Gollin (2002), and set $\alpha=.267$, which is the middle value of three estimates he presents for the U.S. The key assumption underlying this estimate is that the ratio of labor income to total income in the noncorporate sector (which cannot be observed directly) is the same as it is in the corporate sector Two other assumptions made by Gollin with respect to the composition of the surplus in the noncorporate sector lead to values of $\alpha$ equalling 0.227 and 0.336. Below, we discuss how our estimates of productivity change when the value of $\alpha$ changes.

\subsection{The Empirical Measures}

Figure 2 shows our (discrete-time) measures of TFP obtained by using equations (18) and (19) over the 1959Q2-2003Q3 period. Productivity in the consumption goods sector $\left(\theta_{t}\right)$ is displayed in the top panel. Productivity grows rapidly in the early part of the sample, slows down in the 1970s and then declines somewhat. This pattern is similar to that reported by GHK (1997), though they interpret their variable as measuring productivity growth in the economy as a whole. Hornstein and Krusell (2000), however, offer a different interpretation, stating that GHK's measure isolates productivity in the consumption goods sector, instead of the aggregate economy. Under this interpretation, our measure and theirs' can be compared directly. The comparison reveals that our measure does not slow down quite as sharply as their measure over the latter part of the sample. Even so, the

\footnotetext{
${ }^{2}$ The corresponding correlations for the levels of these series are 0.996, 0.999 and 0.976. However, as we show below, the productivity measures are nonstationary
} 
two measures appear to be telling a reasonably consistent story about productivity in the consumption goods sector, a consistency that is especially notable given the very different ways in which they have been constructed.

Aggregate productivity also depends upon productivity in the capital goods sector. Our measure of TFP in the capital goods sector $\left(\mu_{t}\right)$ is shown in the middle panel. It shows little evidence of a slowdown in the mid-1970s, but does accelerate noticeably towards the end of the sample. The bottom panel shows our measure of economy-wide productivity, which is constructed as a Divisia aggregate of productivity in the two sectors, following Whelan(2001). ${ }^{3}$

To provide a better sense of how our constructs compare to more conventional measures, Figure 3 plots our measure of aggregate productivity together with the corresponding measure of multifactor productivity constructed by the Bureau of Labor Statistics (BLS). ${ }^{4}$ To make them easier to compare, both series have been normalized to equal 100 in 1980Q1. Given the very different ways in which these two series are constructed, they turn out to be reasonably close. Note also that our measure is less volatile than the BLS measure; for instance, it does not decline as sharply as the BLS measure does during the recessions in the mid-1970s and the early-1980s. ${ }^{5}$

\footnotetext{
${ }^{3}$ Hulten(1973) provides a set of necessary and sufficient conditions under which the Divisia index is the "...best choice among index numbers.." in that it becomes path independent and thus retains all the information up to an arbitrary normalization of the aggregation problem.

${ }^{4}$ The BLS measure of productivity, as well as notes on its construction, is available on the website: http://data.bls.gov/cgi-bin/surveymost?mp. These data are annual and were only available through 2001 as of January 2004. To plot them at a quarterly frequency, we have used an interpolation routine from RATS.

${ }^{5}$ We have also examined the sensitivity of our productivity measures to alternative values of $\alpha$ used to construct these measures. Specifically, we used the two other values of $\alpha$ from Gollin(2002): $\alpha=0.227$ and $\alpha=0.336$. The low value of $\alpha$ leads to a productivity measure which grows more closely in line with the BLS estimate than the original value of $\alpha$ shown in Chart 3. Nevertheless, we stay with our original estimate of $\alpha$ in what follows, because we prefer the underlying assumption about noncorporate sector income.
} 


\subsection{Examining the behavior of the productivity measures}

In deriving our measures of total factor productivity growth we have imposed no restrictions on the relationship between productivity growth in the two sectors. In principle, long-run changes in the two series could be the result of one or more common factors. Alternatively, at the other extreme, the two series could evolve more or less independently of each other in the long run. In addition, one of the key concerns of this paper is the change in productivity growth rates over time. Did productivity in the capital good sector actually accelerate in the early 1970s? What about productivity in the consumer goods sector?

We take up these issues now, beginning with an examination of the time series properties of our productivity measures. As Figure 2 suggests, both series turn out to be nonstationary, even after we allow for a linear trend. When $\widetilde{\mu}_{t}$ is regressed on one lag plus a trend, the coefficient on the lag term exceeds one. The same regression for $\widetilde{\theta}_{t}$ leads to a coefficient that is less than 1 , but a Dickey-Fuller statistic of -1.7 , which is quite a bit smaller (in absolute terms) than the 5 percent critical value of -3.5 . The augmented Dickey-Fuller test gives similar results. Thus, we cannot reject a unit root in either process. The two series turn out not to be cointegrated either. For instance, when the Dickey-Fuller test is applied to the residual from a regression of $\widetilde{\mu}_{t}$ on $\widetilde{\theta}_{t}$, we get a Dickey-Fuller test statistic of 1.9. ${ }^{6}$ A finding of cointegration would have implied that long-term productivity growth in both sectors was driven by a common trend. However, our finding implies that the two productivity processes are being driven by more than one stochastic trend and that the levels can drift apart, implying that $g_{\mu} \neq g_{\theta}$.

Next, we carry out tests to determine whether the behavior of our productivity measures has changed over time; more specifically, whether the mean growth rates might have changed over our sample. To remain consistent with our theoretical derivations above, we will work under the maintained hypothesis that any breaks that occur are unexpected. The tests we employ are due to Bai and Perron (1998) ${ }^{7}$.

\footnotetext{
${ }^{6}$ For a discussion of various tests for unit roots and cointegration, see Maddala and Kim (1998).

${ }^{7} \mathrm{We}$ are grateful to Pierre Perron for providing us with a copy of his program to perform the
} 
These tests allow for multiple breaks and can be used to detect breaks in the series when neither the dates nor the number of breaks are known.

In testing for breaks, we drop 10 percent of the sample at either end; given a sample of 176 observations, this means that we effectively test for breaks over the dates from 1963Q4 to 1999Q2. Ten percent is also the size of our smallest interval in the tests below; in other words, two breaks cannot occur within 17 quarters of each other. We allow a maximum of 5 breaks over our sample in all of the tests that follow. The limit of 5 breaks is never binding in the sequential tests below.

We present the results from three different tests in Table 1, based on recommendations in Bai and Perron (2000). ${ }^{8}$ The first column presents the results of regressing $\Delta \widetilde{\mu}_{t}$ (which equals the growth rate of TFP for the capital goods sector) on a constant and one lag. ${ }^{9}$ The first entry contains the results from BP's UDmax test, which tests the null hypothesis of no break against the alternative of an unspecified number of breaks (up to our maximum of 5 breaks). The null of no breaks is rejected at the 1 percent level; thus, there is at least one break in the series. Next, we present the results from BP's $\operatorname{Sup}(2 \mid 1)$ test, which tests the null of 1 break against the alternative of 2 breaks. The null hypothesis is rejected at the 10 percent level. The next row shows the break dates identified by this procedure, which turn out to be 1995Q4 and 1973Q1 (in that order). Finally, the sequential procedure only finds the break at 1995Q4, and that is significant at the 1 percent level. A nice feature of the BP procedure is that it gives us confidence intervals for the estimated break dates. The estimated intervals are rather tight, with the 90 percent interval spanning the period from 1993Q1 to 1997Q3.

The second column presents the results for the productivity process in the consumer good sector $(\theta)$. There is evidence of one break in the mean growth rate of this series, which is located in 1978. However, the associated interval is very

calculations below.

${ }^{8}$ According to Bai and Perron (BP), the sequential procedure works best overall, but often can be improved upon by a combination of the UDmax and the Sup(i+1|i) test. For that reason, we present results from all three tests.

${ }^{9}$ Here and in the other regressions in Table 3, lags of the dependent variable are only included if they are significant. 
wide, stretching from 1972Q1 to 1984Q4. ${ }^{10}$

These dates are not out of line with dates found by other researchers using different methods. For instance, the estimated intervals for the $\Delta \widetilde{\theta}_{t}$ break date encompass the early 1970s, which is where many of the papers in the NBER(2001) volume on productivity analysis place the beginning of an extended period of slower productivity growth. Our finding of a break in the $\Delta \widetilde{\mu}_{t}$ process at the end of 1995 is similar to Jorgenson's (2001) finding of a growth resurgence in the U.S. beginning in 1995, which he links to information technology in general, and to a shift in the product cycle for semiconductors, in particular. Similarly, Oliner and Sichel (2000), in a study that measures the contribution of computers to the recent surge in output and productivity growth, also locate the change in the middle of the 1990s.

Significantly, we find no evidence of an acceleration in capital sector productivity growth in the 1970s. There is evidence of a break in the total factor productivity measure for the capital sector $\left(\Delta \widetilde{\mu}_{t}\right)$ during this period, but an examination of the estimated coefficients reveals that the capital sector productivity growth rate actually slowed down over this period.

More generally, the evidence in Table 1 provides information about the relationship between the series and can be used to impose a structure upon them. It is, in particular, consistent with a specification in which long-run productivity growth in the economy can be attributed to two processes: one that affects both sectors and one that affects the capital good sector alone. Under this specification, the productivity processes in the two sectors could be written as:

$$
\begin{gathered}
\Delta \widetilde{\theta}_{t}=A \Delta x_{t} \\
\Delta \widetilde{\mu}_{t}=B \Delta x_{t}+\Delta y_{t}
\end{gathered}
$$

An increase in the growth rate of $y$ in the mid-1990s would account for the observed increase in the growth rate of $\mu$ while a decrease in the growth rate of $x$

\footnotetext{
${ }^{10}$ Based on the results of a simulation study, Bai and Perron(2000) state that confidence intervals tend to be large when breaks are either"too small" or "too large."
} 
during the 1970s would account for the observed decrease in the growth rate of both $\theta$ and $\mu$ at this time.

Given this specification, we can recover an estimate of the $y$ process by estimating

$$
\Delta \widetilde{\mu}_{t}=a \Delta \widetilde{\theta}_{t}+\Delta \widetilde{\mu}_{t}^{r}
$$

Now, $\Delta \widetilde{\theta}_{t}$ can be interpreted as the economy wide shock or the shock that is common to both sectors while $\Delta \widetilde{\mu}_{t}^{r}$ affects the capital sector alone. Also, we now have

$$
\Delta \widetilde{q}_{t}=(1-a) \Delta \widetilde{\theta}_{t}-\Delta \widetilde{\mu}_{t}^{r}
$$

Thus, the relative price is affected by both the common shock and the capital sector shock. Note, in particular, that the relative price of capital goods could fall in response to a positive common shock if $a$ was larger than 1 . That is, the relative price of the capital good would fall in response to positive shocks of either kind in a world where the common shock had a larger impact on the capital goods sector than on the consumption goods sector.

Note that $a=1$ gives us the GHK identification. As (24) indicates, in that case the common shock process has no effect on the relative price of capital and changes in the relative price of capital provide information about technical progress in the capital goods sector. However, if $a \neq 1$, the relative price variable is actually a linear combination of the capital sector process and the process that affects both sectors.

We estimate equation (23) after including a constant, and obtain

$$
\Delta \widetilde{\mu}_{t}=\underset{(19.7)}{0.0068}+\underset{(5.4)}{0.36} \Delta \widetilde{\theta}_{t}
$$

where the t-statistics are shown in parentheses, and the equation has an adjusted $R^{2}=0.14$. The estimated value of $a=0.36$ implies that an increase of one percent in the productivity process that affects both sectors raises $\widetilde{q}_{t}$ by about two-thirds of 
a percent. Note that the estimate of $a$ is less than 1 at any conventional significance level.

Figure 4 plots our estimates of $\Delta \widetilde{\theta}_{t}$ and $\Delta \widetilde{\mu}_{t}^{r}$. From the plot of $\Delta \widetilde{\theta}_{t}$ (see the top panel), the mean growth rate of economy-wide productivity appears to be somewhat higher in the early part of the sample; in the lower panel (which shows the growth rate of productivity in the capital goods sector), the sequence of positive shocks in the late 1990 s is striking.

Column 3 of Table 1 presents the results of the BP break tests for $\Delta \widetilde{\mu}_{t}^{r}$ (the productivity process that affects the capital goods sector alone), where the regression contains one lag of the dependent variable. We find strong evidence of a single break in 1995, as the statistics from both the UDmax and the sequential procedure are both significant at the 1 percent level. The fact that there is no evidence of a break in this process during the 1970s (together with the evidence of a break in both the other series shown in Table 1) supports our interpretation that productivity growth in both sectors declined because of a common shock.

To take account of the evidence from the break test we re-estimated (25) allowing the constant to shift in 1995. Under this specification the estimated value of $a$ turned out to be 0.35 (with a t-statistic in excess of 6) which is practically the same as the original estimate. We also allowed for shifts in 1973 and 1978 to make doubly sure that the estimation was not forcing a common break on the two series; neither one turned out to be significant at even the 50 percent level. Once again, this finding supports the structure we have imposed on the two TFP measures. ${ }^{11}$

\footnotetext{
${ }^{11}$ While the identification we employ is appropriate for our purpose of examining capitalspecific technological progress, the structure of the breaks themselves would, in any case, argue against the reverse identification, which would be one in which $\Delta \widetilde{\mu}_{t}$ was identified as the "common" shock to the economy while the second shock (say, $\Delta \widetilde{\theta}_{t}^{r}$ ) was assumed to affect the consumption goods sector alone. Given that there is no evidence of a break in $\Delta \widetilde{\theta}_{t}$ during the 1990 s, imposing this structure would mean having to argue that the noticeable increase in $\Delta \widetilde{\mu}_{t}$ at this time must have been offset by a sharp decrease in productivity that was specific to the consumption good sector $\left(\Delta \widetilde{\theta}_{t}^{r}\right)$.
} 


\subsection{Implications}

The estimation reveals that productivity shocks which affect both sectors have a larger impact on the consumption goods sector than on the capital goods sector. As a consequence, positive productivity shocks that affect both sectors actually raise the relative price of capital. This has an important implication: the sustained decline in the relative price of capital that is evident in Figure 1 cannot be a consequence of the productivity process that affects both sectors, unless one wants to argue that productivity has been falling over this period.

For the issue at hand, perhaps the more important implication of the finding that $a$ is not equal to 1 in (24) is that the common shock process and the relative price of capital are correlated. Since GHK identify the relative price of capital with capital-specific technological change the implication is that the two measures of technological progress constructed under this identification are correlated. This makes it hard to interpret statements about the contributions of capital-specific technological shocks to either long-run growth or to business cycles. For instance, a change in the growth rate of the common shock process would show up as a change in the growth rate of the relative price of capital, which this identification scheme would interpret as a change in the pace of capital-specific technological progress. Similarly, if the common shock process were to become more volatile (and other things were held fixed), the resulting change in the volatility of the relative price of capital would be interpreted under this identification as an increase in the volatility of capital sector shocks and could show up as an increase in the contribution of capital sector shocks to business cycle fluctuations.

The finding that the estimated value of $a$ in (24) is less than 1 means not only that the two productivity measures constructed under the GHK identification are correlated but that this correlation is negative. This is easily verified. For our

sample period, the correlation between the two series $\Delta \widetilde{\theta}_{t}$ and $\Delta \widetilde{\mu}_{t}^{g}$ (which is how we denote the GHK measure of capital-specific technical progress from now on) turns out to be -0.58 over the 1959Q3-2003Q3 sample. Here, it is worth noting that the correlation between the two untransformed measures of productivity $\left(\Delta \widetilde{\theta}_{t}\right.$ 
and $\left.\Delta \widetilde{\mu}_{t}\right)$ is 0.38 .

The negative correlation induced by this identification is not innocuous. Specifically, it means that periods during which the GHK measure of capital-specific productivity growth goes up will tend to be periods when the measure of economywide productivity $\left(\Delta \widetilde{\theta}_{t}\right)$ goes down. Under this identification, then, periods during which economy-wide productivity decelerates (such as the 1970s) will also appear to be periods when capital-sector productivity picks up.

Table 2 shows how the identification one imposes can affect the inferences that are drawn about changes in productivity growth over time. We show average productivity growth over three different periods; the first one runs from the beginning of 1959 to the end of 1973, the second from the beginning of 1974 to the end of 1990 and the last from the beginning of 1991 to the third quarter of 2003 (which is our last data point). The split between the first and second subsamples is chosen to allow an examination of claims that the rate of growth of capital-specific technological progress accelerated around this time while the second break is chosen to allow comparisons with the results presented in table 3 below.

The first row shows productivity growth rates for $\Delta \widetilde{\theta}_{t}$, which is the common shock. The remaining rows show growth rates for different measures of productivity in the capital goods sector, starting with $\Delta \widetilde{\mu}_{t}$, which measures total factor productivity in the capital good sector, followed by the $\Delta \widetilde{\mu}_{t}^{g}$, which is the GHK measure of capital sector productivity and ending with $\Delta \widetilde{\mu}_{t}^{r}$, the capital sector productivity measure obtained from equation (25) above.

The table shows that the average growth rate of $\Delta \widetilde{\theta}_{t}$ over the 1974-1990 period was noticeably lower than it was over the 1959-1973 period. Nor was this slowdown reversed after 1990; if anything productivity growth in the consumption goods sector slowed a little bit more after that. Total productivity growth in the capital goods sector also slowed sharply after 1973; interestingly, the slowdown was more than reversed after 1990, with capital sector productivity growing some thirty percent faster on average over the 1990-2003 than it did over 1959-1973.

So far, these patterns of growth are not particularly surprising. The next row 
shows capital sector productivity growth as defined by GHK. According to this measure, there is no evidence of a slowdown in capital-sector productivity growth after 1973; in fact it suggests that productivity growth in the capital sector picked up slightly. By contrast, $\Delta \widetilde{\mu}_{t}^{r}$ (the measure of productivity growth in the capital goods sector obtained from equation 25) does not show any evidence of an acceleration after 1973; instead, productivity growth declines by more than 20 percent. Both measures do show a sharp acceleration in capital sector productivity growth after 1990.

It is reasonable to ask how sensitive these results are to the measure of relative prices used here. To provide a check, we repeated this analysis using the relative price measure used in GHK (1997). Because this is an annual measure we also used Poterba's measure of the rate of return on capital. Because of the GHK relative price data, the sample ends in 1990. The results are shown in Table 3. While the relative magnitudes are different, the pattern of results is the same as in Table 2. Productivity in the consumption good sector slows down quite sharply after 1973. There is a similar slowdown in the TFP measure for the capital good sector and in our constructed measure $\left(\Delta \widetilde{\mu}_{t}^{r}\right)$, but not in the GHK measure $\left(\Delta \widetilde{\mu}_{t}^{g}\right)$, which actually picks up slightly after 1973.

Thus, the results using either relative price measure show that TFP growth in the capital sector decelerated in the early 1970s (though not quite sharply as TFP growth in the consumption goods sector). Further, claims of an acceleration in capital-specific technological progress at this time depend upon the use of a productivity measure for that sector that is negatively related to economy wide productivity growth.

\section{Conclusions}

A large body of recent literature has used the relative price of capital as a measure of technological change that is specific to the capital goods sector. We have shown that this assumption is not innocuous, but imposes specific restrictions on the rela- 
tionship between the TFP processes in the capital and consumption goods sectors. We use price data and theoretical restrictions to construct empirical measures of productivity in these two sectors and find that the condition required to use the relative price of capital as a measure of technological progress that is specific to the capital goods sector is rejected by the data. Specifically, we find that the GHK identification leads to a measure of capital sector productivity that is negatively correlated with the productivity process that affects both sectors.

The existence of this correlation makes it hard to determine the exact role that capital sector shocks (identified in this way) play in causing economic fluctuations and calls into question the results of earlier studies that attempt to measure the contribution of capital sector shocks either to business cycles or growth. In addition, it raises questions about the claims of an acceleration in capital sector productivity growth in the 1970s.

While our results lead to a rejection of the identification of the relative price of capital with technical progress in the capital goods sector, they are consistent with a decomposition of the economy-wide productivity process into a process that affects both sectors and one that affects the capital sector alone. Given this representation, we find evidence of a slowdown in the economy-wide productivity process in the 1970s and an acceleration in the capital sector process in the 1990s. 


\section{References}

Bai, Jushan and Pierre Perron. 1998. "Estimating and Testing Linear Models with Multiple Structural Changes," Econometrica, January, pp. 47-78.

—_. 2000. "Computation and Analysis of Multiple Structural Change Models." mimeo.

Cummins, Jason G. and Giovanni Violante. 2002. "Investment Specific Technical Change in the United States (1947-2000): Measurement and Macroeconomic Consequences," Review of Economic Dynamics, pp. 243-284.

Cooley, Thomas F. and Edward C. Prescott. 1995. "Economic Growth and Business Cycles," Ch. 1, in Frontiers in Business Cycle Research, ed. by Thomas F. Cooley. (Princeton:Princeton): 1-38.

Fisher, Jonas. 2002. “Technology shocks matter," Working Paper Series WP-0214, Federal Reserve Bank of Chicago

Gollin, Douglas. 2002. “Getting Income Shares Right,” Journal of Political Economy, vol 110, April, pp. 458-474.

Greenwood, Jeremy, Zvi Hercowitz, and Per Krusell. 1997. "Long-run Implications of Investment-Specific Technological Change," American Economic Review, vol. 87 , no. 3 , June: $342-362$.

Greenwood, Jeremy and Mehmet Yorukoglu. 1997. “1974,” Carnegie-Rochester Conference Series on Public Policy, June, pp. 49-96

Greenwood, Jeremy, Zvi Hercowitz and Per Krusell. 2000. "The Role of Investment Specific Technological Change in the Business Cycle.” European Economic Review, pp. 91-115. 
Hansen, Bruce E. 2001. "The New Econometrics of Structural Change: Dating Breaks in U.S. Labor Productivity," The Journal of Economic Perspectives, Fall 2001, pp. 117-128.

Hornstein, Andreas and Per Krusell. 2000. “The IT Revolution: Is It Evident in the Productivity Numbers?" Federal Reserve Bank of Richmond Economic Quarterly, Fall, pp. 49-78.

Hsieh, Chang-Tai. 2002. "What Explains the Industrial Revolution in East Asia? Evidence from Factor Markets, ” American Economic Review June, pp. 502-526.

Hulten, Charles R. 1973. "Divisia Index Numbers," Econometrica, vol 41, no. 6, November, pp. 1017-1025.

Jorgenson, Dale W. 2001. "Information Technology and the U.S. Economy," American Economic Review, vol. 91, no.1, March: 1-32.

and Zvi Griliches. 1967. "The Explanation of Productivity Change." The Review of Economic Studies 34 (July), pp. 249-283.

Maddala, G.S. and In-Moo Kim. 1998. Unit Roots, Cointegration and Structural Change. Cambridge: Cambridge University Press

NBER. 2001 New Developments in Productivity Analysis. edited by Hulten, Charles R., Edwin R. Dean, and Michael J. Harper. (Chicago:The University of Chicago Press).

Oliner, Stephen D. and Daniel E. Sichel. 2000. “The Resurgence of Growth in the Late 1990s: Is Information Technology the Story?" FEDS Working Paper 2000-20 (May).

Poterba, James M. 1997. “The Rate of Return to Corporate Capital and Factor Shares: New Estimates Using Revised National Income Accounts and Capital Stock Data," National Bureau of Economic Research, Working Paper No. 6263. 
Whelan, Karl. "Balanced Growth Revisited: A Two-Sector Model of Economic Growth," Federal Reserve Board Finance and Economics Discussion Series 200104. 


\section{Table 1: Testing for Shifts in Productivity Growth}

\begin{tabular}{|c|c|c|c|}
\hline Series tested: & $\Delta \widetilde{\mu}_{t}$ & $\Delta \widetilde{\theta}_{t}$ & $\Delta \widetilde{\mu}_{t}^{r}$ \\
\hline \multicolumn{4}{|l|}{ Test: } \\
\hline Udmax & $21.1^{1}$ & $12.0^{5}$ & $24.2^{1}$ \\
\hline $\operatorname{Sup}(2 \mid 1)$ & $7.7^{10}$ & 1.2 & 2.7 \\
\hline $\begin{array}{l}\text { Break dates- } \\
\text { from Sup tests }\end{array}$ & $\begin{array}{l}\text { 1995Q4 } \\
1973 Q 1\end{array}$ & 1978Q1 & 1995Q1 \\
\hline $\begin{array}{l}\text { Break Dates- } \\
\text { from Sequential } \\
\text { Procedure }\end{array}$ & $1995 \mathrm{Q} 4^{1}$ & $1978 Q 1^{5}$ & $1995 \mathrm{Q} 1^{1}$ \\
\hline $\begin{array}{l}90 \% \text { Confidence } \\
\text { Intervals for } \\
\text { break dates }\end{array}$ & 93Q1-97Q3 & 72Q1-84Q4 & 93Q3-98Q4 \\
\hline
\end{tabular}

Notes: ${ }^{1}$ denotes significant at $1 \%,{ }^{5}$ denotes significant at $5 \%,{ }^{10}$ denotes significant at $10 \% . \Delta \widetilde{\mu}_{t}$ and $\Delta \widetilde{\theta}_{t}$ denote TFP in the capital and consumer good sector respectively, while $\Delta \widetilde{\mu}_{t}^{r}$ is a measure of productivity growth in the capital sector as defined in Section 3. 
Table 2: Average Productivity Growth Rates $^{1}$

$\begin{array}{cccc}\begin{array}{c}\text { Productivity } \\ \text { Measure: }\end{array} & \text { 1959Q2-1973Q4 } & \text { 1974Q1-1990Q4 } & \text { 1991Q1-2003Q3 } \\ \Delta \widetilde{\theta}_{t} & 1.0 \% & 0.07 \% & -.12 \% \\ \Delta \widetilde{\mu}_{t} & 2.98 \% & 2.11 \% & 3.72 \% \\ \Delta \widetilde{\mu}_{t}{ }^{g} & 1.98 \% & 2.04 \% & 3.84 \% \\ \Delta \widetilde{\mu}_{t}{ }^{r} & 2.61 \% & 2.08 \% & 3.76 \%\end{array}$

${ }^{1}$ Growth rates shown are actually $\log$ differences multiplied by $4 \times 10^{2}$.

Table 3: Average Productivity Growth Rates Using GHK relative price measure ${ }^{1}$

Productivity

$1959-1973$

1974-1990

Measure:

$\begin{array}{lll}\Delta \widetilde{\theta}_{t} & 0.72 \% & -0.32 \% \\ \Delta \widetilde{\mu}_{t} & 0.39 \% & 0.30 \% \\ \Delta \widetilde{\mu}_{t}^{g} & 0.33 \% & 0.34 \% \\ \Delta \widetilde{\mu}_{t}^{r} & 0.51 \% & -0.41 \%\end{array}$

${ }^{1}$ Growth rates shown are actually log differences multiplied by $10^{2}$.

Note: In both tables, $\Delta \widetilde{\theta}_{t}$ denotes TFP growth in the consumer goods sector, while the remaining three variables present alternative measures of productivity growth related to the capital goods sector. See Section 3 for details. 
Figure 1: The Relative Price of Capital*

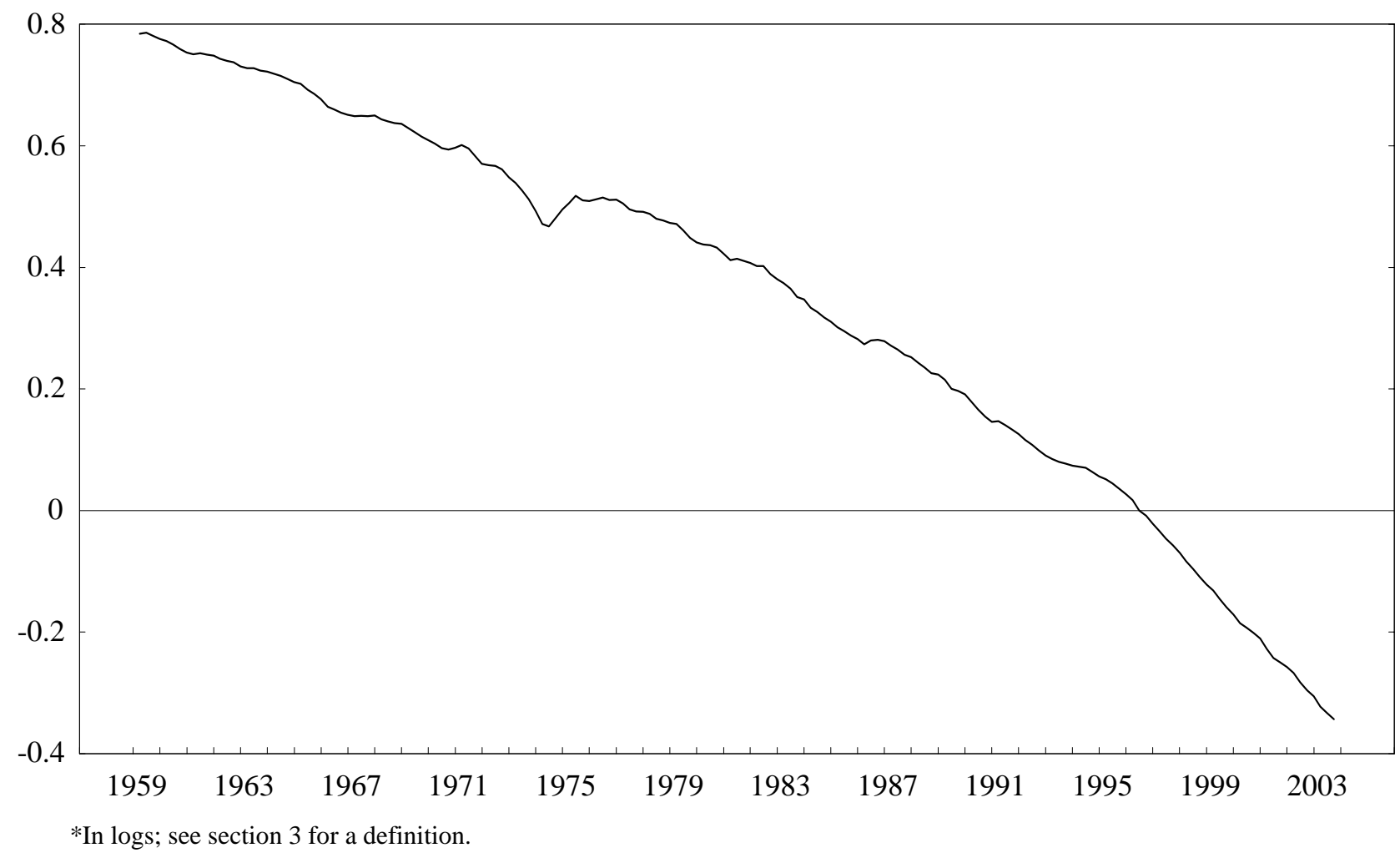




\section{Figure 2: Measures of Productivity from a Two Sector Model}
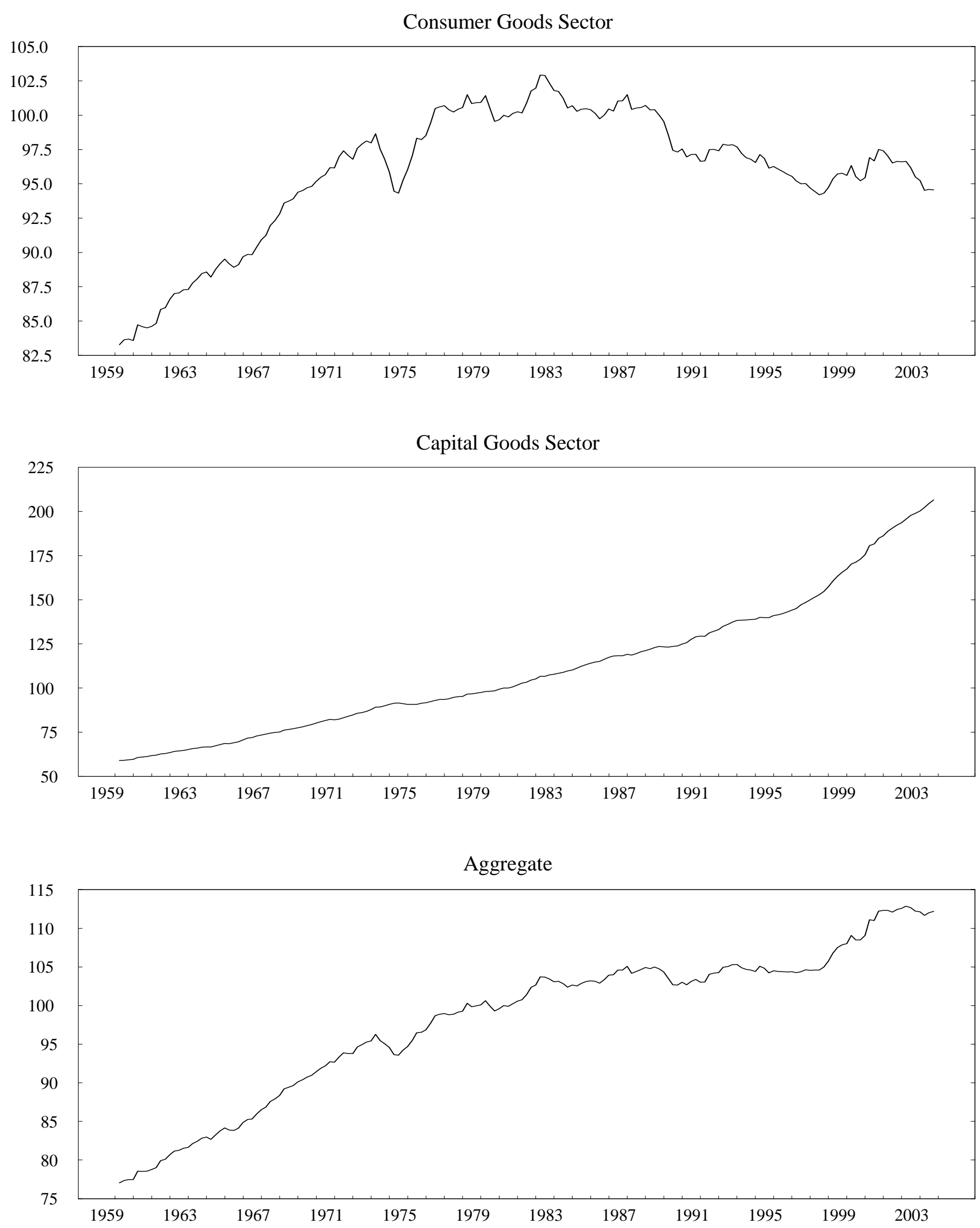


\section{Figure 3: Alternative Measures of Productivity}

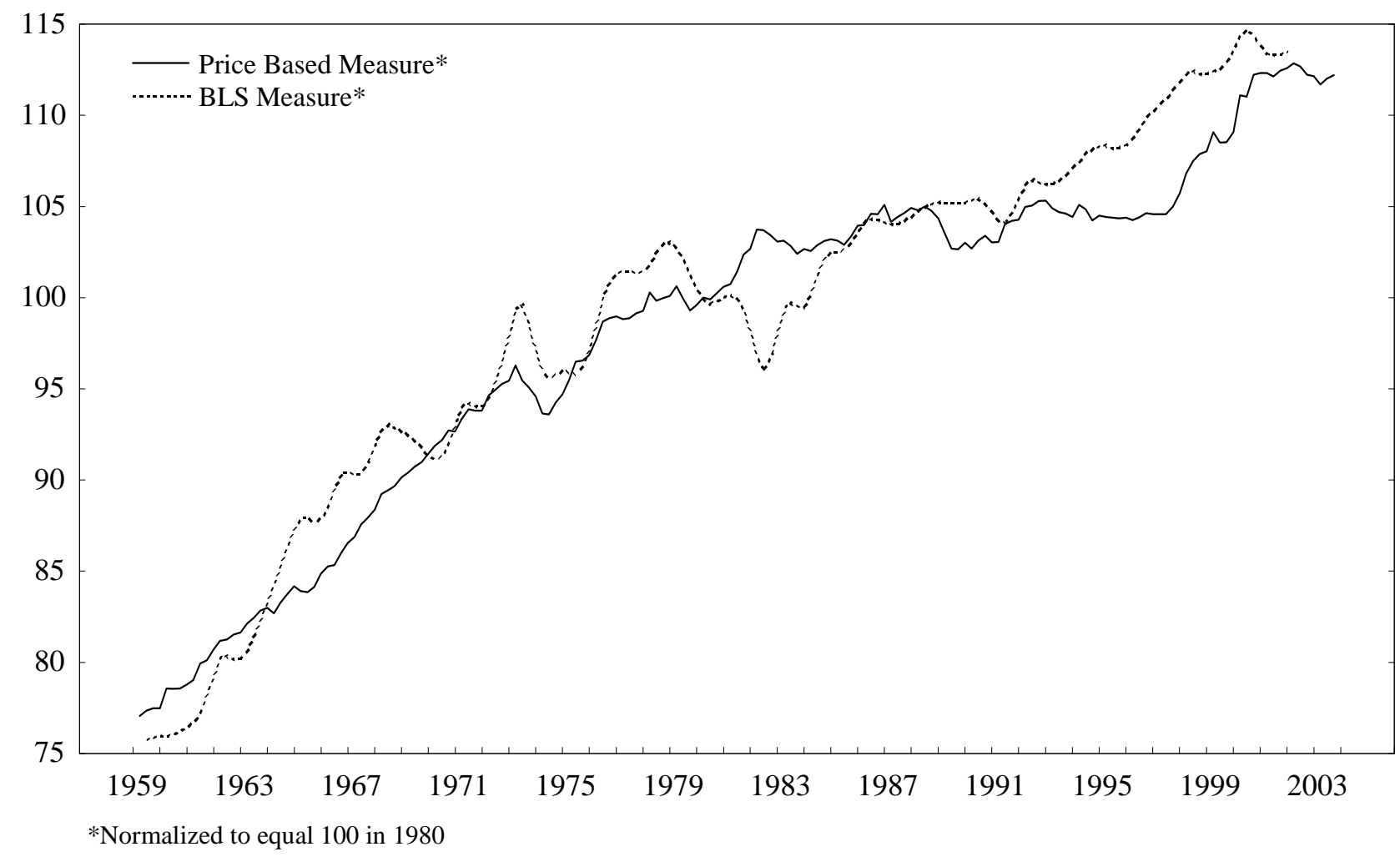


Figure 4: Orthogonal Measures of Productivity Growth

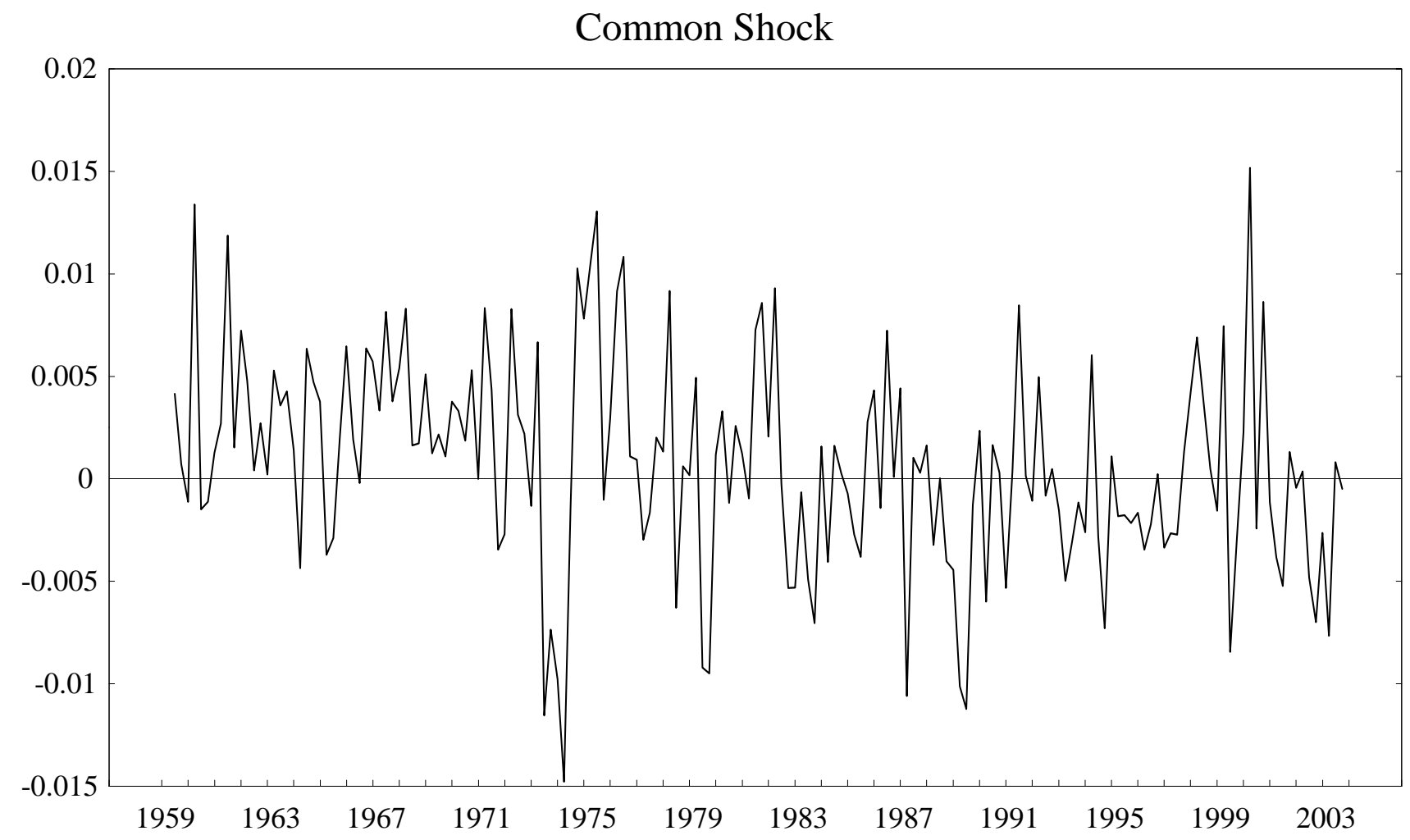

Capital Goods Sector Shock

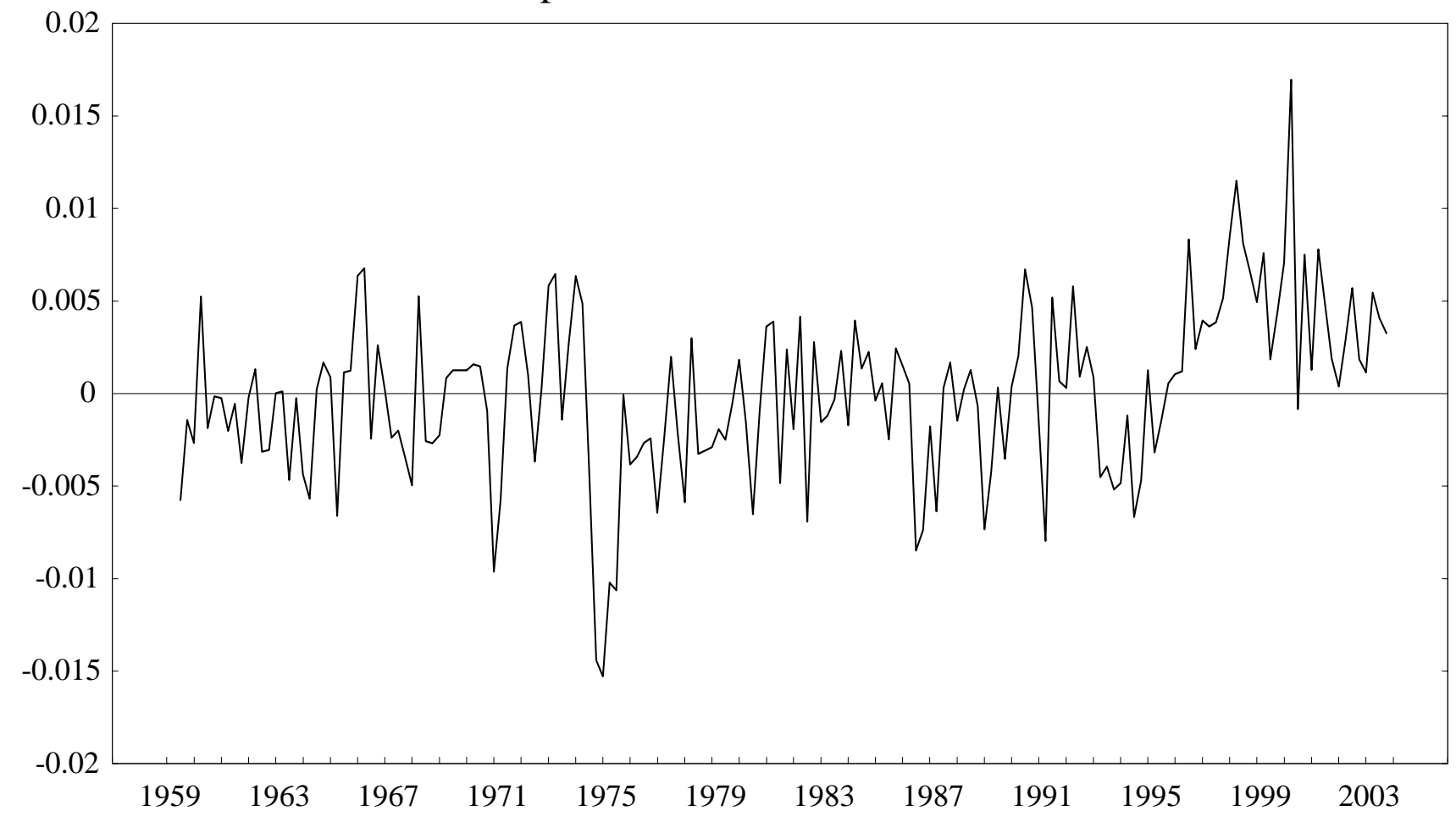

